\title{
A NÃO MATERNIDADE POR OPÇÃO: DEPOIMENTOS DE MULHERES QUE NÃO QUEREM TER FILHOS
}

\author{
NON-MATERNITY BY CHOICE: STATEMENTS FROM WOMEN WHO DO NOT WANT TO HAVE CHILDREN
}

\section{RESUMO}

O conceito de maternidade reflete um sistema patriarcal que reforça a imposição social de constituir família, cabendo à mulher a responsabilidade compulsória de gerar e criar filhos. Todavia, é considerável o número de mulheres que não aspiram à maternidade atualmente, prova disso são as quedas nas taxas de natalidade e novas formas de organização familiar. Trata-se de uma pesquisa qualitativa e quantitativa, que coletou dados por meio de um questionário online, construído através da plataforma Formulários Google, o qual foi respondido por 310 mulheres que afirmaram não desejar serem mães. Os dados para a análise foram organizados considerando as questões mais frequentes que permeiam a temática: Maternidade compulsória: maternidade como obrigação e destino inquestionável da mulher; Arrependimento: afirmação externa de que se trata de uma escolha momentânea que gerará arrependimento; Maternidade é benção: afirmações que colocam o filho como principal fonte de felicidade. Destaca-se a possibilidade de compartilhar socialmente a opção pela não-maternidade, mas não sem julgamentos, os quais estão vinculados à ideia de maternidade compulsória.

Palavras-chave: Maternidade. Não-maternidade. Gênero. Análise de conteúdo.

\begin{abstract}
The concept of motherhood reflects a patriarchal system which reinforces the social imposition of starting a family, laying on women the compulsory responsibility of bearing and raising children. However, there is a considerable number of women which, nowadays, do not aspire to motherhood, an evidence of this are the low birth rates and the new types of familiar organization. This is a qualitative and quantitative research, which collected data through an online questionnaire, built using the Google Forms platform, which was answered by 310 women who said they did not want to be mothers. The data were organized in the following categories: Compulsory motherhood: motherhood as an obligation and unquestionable destiny for women; Regret - most of the answers point to the external statement that this is not about a decision, but a momentary choice which will cause regret. Motherhood is a blessing - statements that consider the child as the main source of happiness. It is highlighted the possibility of saying about the option for non-motherhood and sharing, but not without judgment and connected to an idea of compulsory motherhood.
\end{abstract}

Izabel Cristina Soares

Universidade Estadual do Centro-Oeste-UNICENTRO. Email: izabelc.soaress@gmail.com

Kátia Alexsandra dos Santos

Universidade Estadual do Centro-Oeste-UNICENTRO. Email: kalexsandra@unicentro.com 
Keywords: Motherhood. Non-motherhood. Gender. Content analysis.

\section{Introdução}

A maternidade ainda é vista como fator biológico, altamente incentivado e até mesmo imposto socialmente à mulher adulta, produzindo-se o efeito de que o modelo de sociedade patriarcal permanece enraizado na contemporaneidade. Com o movimento feminista centrado em lutas como a descriminalização do aborto e outras pautas relacionadas aos direitos reprodutivos, o conceito de maternidade ganha certo destaque, levando a um questionamento: como se fixou socialmente a ideia de um "instinto materno" natural, que coloca a mulher interligada com a função de ser mãe?

A mulher contemporânea pode possuir diversos objetivos pessoais que, muitas vezes, não incluem a formação de uma família tradicional ou ainda a geração de um filho, contrariando o esperado, pois, segundo Santos (2013), há uma cobrança da sociedade sobre a mulher para que exerça a maternidade, especialmente se possui um relacionamento estável, boa situação financeira e idade para gerar e criar um filho. O que fica em segundo plano nesse tipo de situação é a sua vontade. Assim, poderíamos nos questionar: por que, mesmo tendo liberdade de escolha, mulheres que optaram por não terem filhos sentem-se pressionadas a justificar sua opção? Enquanto as mulheres que decidem ser mães não são questionadas acerca de sua escolha, uma vez que se colocam do lado do discurso corrente, esperado para uma mulher.

Desse modo, considerando as questões que permeiam a possibilidade de "escolha" entre ser ou não ser mãe na atualidade, este trabalho traz o relato de uma pesquisa exploratória, qualitativa, de caráter descritivo e empírico acerca do discurso de mulheres que optaram por não ter filhos. Sendo um trabalho que apresenta dados de linguagem, falar sobre não-maternidade é falar sobre maternidade, de modo que consideramos a cobrança generalizada na sociedade e os fatores sociais e ideológicos que perpassam a temática. Assim, o trabalho justifica-se, uma vez que aborda uma questão atual e que ainda não foi estudada a contento. Para isso, discutiremos acerca da construção da maternidade, para depois apresentar os dados coletados por meio de um questionário.

\section{A construção da maternidade}

Maternidade e feminilidade são elementos discursivamente ligados, de modo que, para apresentarmos as condições de produção no período contemporâneo, é preciso remontar a alguns elementos da constituição da maternidade na história. 
Simone de Beauvoir, em afirmação bastante conhecida e que ainda reverbera, afirmou que "ninguém nasce mulher: torna-se mulher" (BEAUVOIR, 1949, p.9). Tal máxima poderia muito bem aplicar-se na questão da maternidade: sendo ela uma construção social feita sob a figura feminina (MANSUR, 2003), de modo que podemos dizer que não se nasce mãe e nem com o que é chamado popularmente de "instinto materno" e, sim, adquire-se e constrói-se a ideia e a prática da maternidade. Elisabeth Badinter (1980/1985) discorre acerca desse termo, desnaturalizando-o na clássica obra Um Amor Conquistado: O Mito do Amor Materno:

O amor materno é apenas um sentimento humano. E como todo sentimento, é incerto, frágil e imperfeito. Contrariamente aos preconceitos, ele talvez não esteja profundamente inscrito na natureza feminina. Observando-se a evolução das atitudes maternas, constata-se que o interesse e a dedicação à criança se manifestam ou não se manifestam. A ternura existe ou não existe. As diferentes maneiras de expressar o amor materno vão do mais ao menos, passando pelo nada, ou o quase nada. (BADINTER, 1980/1985, p. 22-23).

Badinter (1980/1985) apresenta uma distinção entre instinto, que seria algo natural, inato, e amor materno, algo construído. Fala, ainda, sobre a insuficiência de gerar: é preciso cumprir o dever da maternidade em sua completude, através da maternagem e da educação dos filhos. Para isso, uma série de práticas e deveres são destinados à mãe, e, mesmo diante de outras perspectivas sociológicas e culturais, como um entendimento destoante das práticas maternais em outras sociedades, recusa-se a questionar tal noção de amor inerente à maternidade. Desse modo, compreende-se como resultado do instinto materno, a vocação natural para o cuidado e a educação dos filhos:

O amor materno foi por tanto tempo concebido em termos de instinto que acreditamos facilmente que tal comportamento seja parte da natureza da mulher, seja qual for o tempo ou o meio que a cercam. Aos nossos olhos, toda mulher, ao se tornar mãe, encontra em si mesma todas as respostas à sua nova condição. (BADINTER, 1980/1985, p. 20).

Partindo da compreensão da prática da maternidade como incentivada e reforçada familiarmente e socialmente, questionamos qual é o posicionamento da mulher que optou pela não maternidade, ou seja, escolheu não gerar e nem criar filhos, diante de uma sociedade que prega esse amor materno como intrínseco à própria feminilidade, pressionando-as a cumprir esse dever social e moral.

Ao remontarmos ao período colonial, é possível afirmar que predominam discursos em torno da valorização da família e dos bons costumes, sustentados por 
uma lógica patriarcal que se mantém até os dias de hoje. Nesse momento, iniciouse na França, um movimento protagonizado por mulheres brancas, de classe alta, que abordou pautas como a liberdade do corpo da mulher, pílulas contraceptivas gratuitas e o aborto opcional legalizado (SCAVONE, 2001), conquistas essas que possibilitariam a escolha pela não maternidade. Sabemos que essas questões ainda são pauta de luta das mulheres na atualidade e, nesse sentido, o movimento feminista foi determinante para se começar a pensar a partir da ótica das mulheres e não mais de uma sociedade predominantemente machista.

Visto que um dos propósitos do feminismo também passa pela discussão acerca da quebra de padrões e estereótipos de gênero, relaciona-se diretamente à maternidade. Se formos explorar os motivos pelos quais o sexo masculino não é constantemente cobrado a exercer a paternidade, uma vez que não se fala em “instinto paterno", veremos que o mesmo critério não se aplica à mulher, para a qual a maternidade é tomada como um fator biológico e natural, vinculado ao cuidado e à afetividade, enquanto a paternidade é vista como fator social. A escritora feminista Joan Wallach Scott (1998), em seus estudos sobre o movimento feminista francês, retrata os papéis de gênero na família na revolução de 1848 :

A família, assim como a propriedade, eram mencionadas como "direitos sagrados", nos debates sobre ordem política, ocorridos em 25 de julho de 1848. Nestes, a maternidade nem mesmo era cogitada, porque se assumia como uma função natural, algo automático, evidente, recebido, uma dádiva. A paternidade, entretanto, era discutida como um direito. Era vista como uma relação política assegurada por via de instituições, como o casamento e o contrato social, e de práticas simbólicas, como a de dar nome aos filhos (SCOTT, 1998, p. 115).

Assim, percebe-se que a maternidade não era uma escolha para as mulheres no século XIX, mas, sim, uma forma de "cumprir seu papel de mulher", o que nos leva a refletir se algo mudou em relação à maternidade desde aquela época e se as mulheres do século XXI são realmente livres para não exercer a maternidade, caso esta seja sua opção.

Embora as discussões acerca da temática da não-maternidade tenham se popularizado atualmente, a ausência da vontade de ter filhos já era debatida em outros contextos. No capítulo "A mãe" da obra O Segundo Sexo (1949), Beauvoir inicia descrevendo acerca das práticas de interrupção da gravidez e da falsa moral das políticas francesas sobre as questões de controle de natalidade. Nesse momento, exemplifica através de histórias de mulheres de diferentes idades, classes sociais, casadas ou solteiras, mães ou não-mães que, em muitos casos, o que as levava a praticar o abortamento era o simples fato de rejeitarem a maternidade, o que vai de encontro aos argumentos relacionados à falta de recursos financeiros, ausência de um companheiro, imaturidade, entre outras justificativas utilizadas para explicar 
os motivos pelos quais uma mulher pode não querer ter filhos. Beauvoir menciona, ainda, a responsabilidade das políticas públicas no que diz respeito à maternidade compulsória, uma vez que estão relacionadas a políticas reprodutivas:

O controle de natalidade e o aborto legal permitiriam à mulher assumir livremente suas maternidades. Na realidade, são em parte uma vontade deliberada e em parte o acaso que decidem da fecundidade feminina. (...). Mas acontece, em compensação, que se ache muitas vezes obrigada a gerar contra sua vontade. Gravidez e maternidade são vividas de maneira muito diferente, caso se desenvolvam na revolta, na resignação, na satisfação, no entusiasmo. É preciso considerar que as decisões e os sentimentos confessados da jovem mãe nem sempre correspondem a seus desejos profundos. (BEAUVOIR, 1949, p. 289-290).

Mais recentemente, o fenômeno da não maternidade tem sido objeto de discussão. Obra emblemática, nesse sentido, é o texto Mães Arrependidas, da pesquisadora israelense Orna Donath (2016). Contudo, há discussão acerca de formas de negação da maternidade que remontam ao período colonial no Brasil, conforme já descrito por Renato Pinto Venâncio (2012) em Maternidade Negada, artigo do livro História das Mulheres no Brasil, organizado por Mary Del Priore (2012). Venâncio descreve sobre o abandono de bebês, prática comum no período colonial, destacando algumas razões pelas quais as mulheres o faziam, como a pobreza ou para "encobrir nascimentos ilegítimos" (p. 198), expressão que se refere aos filhos enjeitados de mulheres brancas solteiras ou frutos de adultérios.

Todavia, cita-se também a ausência do amor materno quando não havia, na prática do abandono ou da entrega de enjeitados, os motivos de proteção já citados anteriormente. A essas mulheres eram atribuídos adjetivos como "desalmadas e egoístas" (p. 202), o que aponta para a já existência de uma norma relacionada à maternidade. Venâncio (2012) destaca, entretanto, as distinções na interpretação do abandono: quando vindo de mulheres pobres, em sua maioria escravas ou operárias, era visto como uma salvação da criança, na intenção de protegê-la da escravidão e da miséria, o que dá margem para o entendimento de uma outra forma de exercer o amor materno: o de proteção através da entrega para outra família ou à chamada assistência pública.

Tais considerações de Venâncio (2012) viabilizam o debate acerca de uma distinção entre o desamor aos filhos e a rejeição à maternidade. Nesse sentido, Donath (2016) discorre sobre a questão do arrependimento, apresentando relatos de mulheres que declaram amor aos seus filhos, mas arrependem-se da maternidade. A autora ainda analisa a falsa ideia de possibilidade de escolha sem interferências, que é facilmente rebatida quando cita alguns dos argumentos, ainda atuais, utilizados na convenção social da maternidade: fatores biológicos, pois engravidar, parir e amamentar são funções exclusivas do corpo feminino; fatores históricos e culturais, 
que reafirmam o potencial reprodutivo; validação da feminilidade, uma vez que a maternidade estabelece uma função para a mulher na sociedade; e, por fim, a esquiva do julgamento social destinado àquelas que recusam a maternidade: defeituosas, egoístas, dignas de pena e frias, cujas vidas são vazias e solitárias.

Badinter (1980/1985) e Venâncio (2012) citaram a insuficiência do gerar e parir, e destacaram que havia, ainda, uma forma padrão de se exercer a maternidade. A contemporaneidade não trouxe muitas mudanças: em Mães Arrependidas, Donath (2016, p. 52) discorre acerca da manutenção da função do cuidado dos filhos designado às mulheres, apontando que as ideias de instinto materno e de natureza feminina seguem como argumentos popularmente indiscutíveis:

(...) essa descrição da "natureza feminina", usada para justificar a obrigação das mulheres de serem mães, também é usada para reforçar a ideia de que elas são dotadas de um instinto maternal congênito e de uma espécie de caixa de ferramentas inata que induz as mulheres, mais que os homens, a criar os filhos que elas deram à luz ou adotaram, e a cuidar deles(...).

Nesse sentido, além da função automática do cuidado, este ainda apresentase carregado de exigências, que dizem respeito à conduta da mulher-mãe validada na atualidade, tais como paciência infinita, necessidade constante de buscar aprimorarse, negligência com as próprias necessidades, participação ativa nas atividades dos filhos, manutenção da carreira profissional e de um padrão estético (DONATH, 2016).

Diante da existência da maternidade como propósito imprescindível na experiência feminina, faz-se necessário o debate visando à desvinculação dos papéis "mulher" e "mãe". Sobre esse assunto, além da obra já citada de Donath (2016), têm sido produzidos atualmente textos e artigos acadêmicos que problematizam a noção de maternidade compulsória e trazem a expressão "não-maternidade" através de perspectivas variadas. Podemos citar pesquisas como as de Fidelis e Mosmann (2013) e Patias e Buaes (2009), que entrevistaram cinco e seis mulheres, respectivamente, que optaram pela nao-maternidade. A análise qualitativa apontou para a escolha de priorizar a carreira, o que não impediu as pressões sociais com as quais lidaram ao declarar sua opção. Em 2012, as autoras Patias e Buaes deram continuidade ao estudo, entrevistando, aparentemente (pelo número e idade das participantes descrito em ambos os estudos), as mesmas mulheres, a fim de compreender suas identidades. A análise apontou que as participantes têm suas vivências atravessadas pela negação da maternidade (PATIAS \& BUAES, 2012). Por fim, em pesquisa com método clínico-qualitativo, Rios e Gomes (2009) entrevistaram quatro casais (compostos por pessoas com mais de 35 anos), a fim de discutir a decisão conjunta de não ter filhos em casamentos heterossexuais contemporâneos. Os resultados apontam que as mulheres relatam maior pressão social vinda tanto da família quanto de amigas/ conhecidas do que os seus companheiros. 
Tais produções se fazem necessárias ao apresentar os desdobramentos acerca da temática e dar visibilidade às mulheres que desviam da norma e escolhem não vivenciar a experiência da maternidade. Contudo, percebe-se que a maioria das pesquisas abordam o fenômeno qualitativamente, com poucos participantes. Nesse sentido, a presente pesquisa procura olhar o fenômeno de maneira mais abrangente em termos numéricos, uma vez que se compreende que não se trata de um fenômeno localizado e minoritário.

\section{Perspectiva metodológica}

Como dito anteriormente, esta pesquisa pode ser classificada como exploratória e descritiva, de caráter qualitativo e quantitativo. A pesquisa exploratória caracteriza-se pelo tipo de investigação que pretende levantar discussões acerca de tema ainda não suficientemente explorado na literatura, fenômeno atual e que merece levantamento de dados, ainda iniciais (GIL, 2002). Dito isso, o caráter descritivo coloca-se, uma vez que não temos a pretensão de explicar ou elaborar relações de causa e efeito, mas apresentar e discorrer sobre as formas de constituição dos discursos das mulheres que afirmam optar por não serem mães. Para a análise dos dados, fazemos uso da Análise de Conteúdo (BARDIN, 2011).

A Análise de Conteúdo que escolhemos para tratar os dados de linguagem é a categorial temática, que se caracteriza como uma técnica que permite fazer levantamento de temas que emergem dos dados verbais. Nesse caso, os temas emergiram das respostas das participantes ao questionário acerca da decisão pela não maternidade. Assim, o instrumento utilizado para coleta de dados foi um questionário, disponibilizado através de uma plataforma online e que poderia ser respondido de modo anônimo, contendo alternativas que buscaram coletar dados mais objetivos como faixa etária, classe social, status de relacionamento, orientação sexual e questionando se já houve intenção de passar pela experiência da maternidade anteriormente, pergunta que possibilitava apenas resposta "sim" ou "não". Sobre a temática da não-maternidade em si, questionou-se, por meio de perguntas dissertativas, acerca dos motivos que levaram a mulher a optar por não ter filhos, e também sobre a existência de interferências e opiniões por parte de seu meio social e afetivo. As últimas perguntas diziam respeito ao ato de compartilhar tal escolha com seu meio, solicitando que as participantes especificassem "com quem" compartilhavam e que tipo de respostas costumavam ouvir nestas situações.

O questionário foi divulgado a partir de redes sociais das pesquisadoras e compartilhamento de outras pessoas. O instrumento ficou disponível durante 15 dias e recebeu 310 respostas. Dado o número de participações, optamos por fechálo, entendendo que já havia número suficiente de respostas para subsidiar a análise, atendendo a um critério de saturação, ou seja, repetição no conteúdo das respostas. 
As respondentes tinham em sua maioria, 42,6\%, entre 26 e 33 anos; $29 \%$ de 18 a 25 anos; $20,3 \%$ de 34 a 40 anos; $6,5 \%$ de 41 a 50 anos e apenas $1,6 \%$ acima de 50 anos. No que se refere ao tipo de relacionamento, 36,5\% eram solteiras, 32,9\% casada ou em união estável; 31\% namorando e 2,6\% em relacionamento ou casamento aberto. No que tange à orientação sexual, $77,7 \%$ se declaram heterossexuais e 16,5\% bissexual, apenas 4,5\% se declara lésbica e 1,3\% Outro. A renda é variável, mas a amostra apresenta poucas participantes com renda até um salário mínimo (4,5\%) ou sem renda (3,9\%). O restante divide-se em: 31,3\%, recebe de 3 a 5 salários mínimos; 30,6\% de um a três; e 29,7\% acima de 5 salários.

A seguir, apresentaremos a análise dos dados, na qual optamos por não identificar as participantes, já que foram muitas e não seria relevante para a análise dos dados. Serão apenas utilizados alguns fragmentos de respostas dadas no questionário, a fim de exemplificar as questões que permeiam o tema.

\section{Análise}

Inicialmente, é preciso mencionar as escolhas que fizemos ao definir nosso objeto de estudo. Dentre uma rede de possibilidades de discursos que circulam em torno da maternidade, optamos justamente por trabalhar com o que surge na contramão: o discurso sobre a não-maternidade por opção. Tal escolha justifica-se pelo espaço que vem sendo dado a esse discurso e simplesmente pelo fato de que hoje, tendo em vista as condições sociais e históricas, é possível falar sobre o não desejo pela maternidade. Por si só, isso já significa um deslocamento em relação ao que circulava anteriormente em torno da maternidade e do papel da mulher na sociedade. Aponta ainda para o fato de que há outros papeis que ela pode assumir, relacionados ao trabalho e até mesmo às relações conjugais hetero e homossexuais.

Contudo, embora já seja possível falar sobre a questão da não-maternidade, tal discurso ainda circula em número muito menor quando relacionado aos discursos sobre o desejo de ser mãe, conforme aponta Santos (2013), em seu trabalho acerca dos discursos sobre a maternidade.

Cabe destacar que a maioria das participantes, conforme se pode observar na descrição apresentada anteriormente, possui renda mensal de 3 a 5 salários mínimos (31,3\%), sendo que uma outra parte significativa (29,7\%) possui acima de 5 salários mínimos. Esses dados têm relação com a ocupação informada pelas participantes: 91 respondentes são professoras e 51 são estudantes. Sobre esses dados, considerase o fato de que as pesquisadoras estão inseridas no ambiente universitário e, uma vez que o questionário foi divulgado e compartilhado através de suas redes sociais, explica-se o caráter da amostra de mulheres que responderam ao questionário. Outras profissões também apareceram com maior frequência, como biólogas (15), pesquisadoras acadêmicas (15), psicólogas (13), fonoaudiólogas (11), advogadas (10), funcionárias públicas (10), autônomas (9) e administradoras (8). Tais ocupações, em 
sua maioria, exigem um maior grau de escolaridade e disponibilidade que possuem relação com variáveis como carga horária destinada ao estudo/trabalho, situação financeira e dedicação à carreira profissional daquelas que as exercem. Esse contexto cria possibilidades para que mulheres tenham aspirações que não dizem respeito à maternidade.

Um dado que chama a atenção é que a maioria das mulheres que responderam ao questionário está em algum tipo de relacionamento, ou seja, quando se discute a opção pela não maternidade ela não parece estar ligada ao fato de não ter um companheiro/a, embora algumas respostas apontem para isso. Uma das primeiras perguntas questionava se as mulheres já tinham sentido vontade de serem mães em algum momento da vida: $54,2 \%$ responderam que $\operatorname{sim}$ e $45,8 \%$ responderam que não. Esse dado nos leva a questionar se, de fato, as mulheres que responderam ao instrumento que utilizamos "optaram" por não serem mães. A pergunta seguinte, que solicitava a explicitação dos motivos que levaram a essa escolha, nos aponta alguns elementos, os quais serão apresentados por meio das categorias de análise seguintes. Esta não era uma pergunta obrigatória, de modo que foram obtidas 239 respostas.

\section{Maternidade Compulsória}

Uma das perguntas solicitava que as mulheres respondessem se já se sentiram pressionadas a serem mães, $85,1 \%$ disseram que sim, contra apenas 14,9\% que responderam negativamente. A seguir, perguntávamos de onde/quem vinha essa pressão. A essa pergunta era possível dar mais de uma resposta, de modo que obtivemos os seguintes resultados: 80,1\% família; 44,6\% de amigos; 13,1\% cônjuge; $35,6 \%$ colegas de trabalho; $45,3 \%$ por parte de conhecidos; $32,2 \%$ pela mídia; $27,3 \%$ Instituições Religiosas; 65,2\% sociedade em geral; 2,6\% Outro. Esses números ratificam o que aponta a literatura acerca da cobrança da maternidade por parte da família, conhecidos, instituições religiosas e sociedade em geral. Nota-se que as categorias com maior percentual (família, instituições religiosas e sociedade em geral) dizem respeito a algo já mencionado anteriormente: o discurso pró-natalidade provém, em grande parte, de uma ideia de maternidade advinda dos conceitos cristãos, que, por sua vez, embasam o ideal familiar: "Deus mandou procriar".

Destaca-se nesse dado o baixo percentual de pressão por parte do cônjuge, o que vai de encontro ao senso comum que afirma que as mulheres acabam tendo filhos para manter ou melhorar o relacionamento. É claro que esses resultados dizem respeito especificamente ao recorte do grupo de mulheres que participaram desta pesquisa. Seriam necessários outros estudos para generalizar essas afirmações, mas elas já apontam para elementos importantes na atualidade. Isso é ratificado por estudos como os de Rios e Gomes (2009a; 2009b), que discutem sobre a decisão 
conjunta de não ter filhos, algo aparentemente comum na contemporaneidade, sobretudo em casais que possuem certa estabilidade financeira.

Perguntamos a seguir se as mulheres compartilham essa decisão com outras pessoas e as respostas que obtivemos foram em maioria $(32,2 \%)$ o compartilhamento da escolha com amigas(os), dando preferência àquelas/es que também não desejam a maternidade. O compartilhamento com a família veio em seguida $(26,7 \%)$, com algumas especificações como "com minha mãe”, "com meus pais", “com minha irmã", porém, tais respostas foram todas categorizadas em "família'. A terceira resposta mais comum foi a partilha da decisão com os/as cônjuges (19,3\%), porém, deve-se considerar que mais de um terço das respondentes se declararam solteiras. Outras categorias, com menor quantidade de respostas, foram "todos" (15,4\%), “com quem pergunta” (12,5\%), “colegas" ( $8,2 \%)$ e "não compartilho minha decisão” $(6,7 \%)$, o que aponta para uma possível permissão social em declarar sua escolha, porém, sem a garantia de que não haverá interferências, considerando a estatística já mencionada de mulheres que disseram se sentir pressionadas a serem mães $(85,1 \%)$. Em diálogo com isso, as próximas categorias discorrem acerca dos conteúdos mais abordados como forma de resposta à verbalização da escolha pela não maternidade.

\section{Arrependimento}

A última pergunta solicitava que as mulheres reproduzissem o que costumam ouvir quando compartilham suas escolhas. As respostas se organizaram nas seguintes subcategorias:

A primeira diz respeito à afirmação de que não se trata de uma decisão, mas de uma escolha momentânea. O enunciado mais comum que aparece, portanto, quando se comunica a decisão de não ser mãe, segundo as participantes é: "você vai mudar de ideia" (12,4\%), sendo que o principal argumento elencado é "você é muito nova ainda”. Destaca-se que as participantes do estudo estão, na maioria $(42,6 \%)$ entre 26 e 33 anos, apenas $29 \%$ estão entre 18 a 25 anos, o que justificaria o argumento. Segundo dados do IBGE, em pesquisa realizada em 2013, a idade média da primeira gestação de mulheres na faixa entre 18 e 49 anos de idade é 21 anos (IBGE, 2013) . Cabe destacar, entretanto, que o dado mencionado não leva em consideração gravidez de adolescentes, o que baixaria consideravelmente a idade média da primeira gravidez das brasileiras.

Em contrapartida, ainda que a média de idade seja essa ( 21 anos) ou ainda menor, é preciso considerar que, ao longo dos anos, juntamente com as mudanças nas possibilidades de atuação social, política e profissional das mulheres, vem aumentando a idade da primeira gravidez, passando para a casa dos 30 anos

1 Os fragmentos das respostas das participantes foram destacados no texto por meio de aspas e negrito (e somente negrito quando falas são maiores e foram recuadas no mesmo formato de citações longas). Optamos por não fazer uso de nomes fictícios, tendo em vista o grande número de participantes e o fato de essa identificação não ser relevante para os propósitos e achados da pesquisa. 
(XIMENES \& OLIVEIRA, 2004). Nesse sentido, há o depoimento de participantes do nosso estudo, que contrariam o argumento acerca da mudança de ideia, utilizado pelas pessoas que ouvem acerca da decisão pela não maternidade: “Quanto à família nunca dei espaço para questionarem e isso vem desde pequena e hoje próxima de fazer 40 anos meu posicionamento é o mesmo."

Conforme Alves et al. (2017), dos anos 1980 até 2010, houve significativas mudanças nos arranjos familiares: diminuição do modelo hegemônico de família (casais com filhos diminuíram de $65 \%$ para 52,5\%). Segundo os autores "isso aconteceu devido à queda da fecundidade, ao maior número de separações e à maior esperança de vida, especialmente entre as mulheres" (2017, p. 45). A fim de ponderar acerca da questão da idade gestacional, seria necessária uma perspectiva interseccional, que levasse em conta, principalmente, um recorte de classe, que parece separar as ocorrências de primeiras gestações entre planejadas e não planejadas.

Ainda na linha dos motivos apresentados por terceiros, considerando, sobretudo, a expectativa de vida atual das mulheres, outra categoria mencionada é o arrependimento $(9,2 \%)$, que traz como principal argumento a possibilidade de ficar sozinha na velhice: "que eu vou me arrepender de não ter filhos.... que não terei ninguém pra cuidar de mim na velhice...e coisas do gênero”. Soma-se a isso, ainda, o argumento do amor, designado como "verdadeiro" apenas na experiência com filhos: "Que no futuro vou me arrepender de não ter experimentado o verdadeiro amor."

Uma parcela, ainda que menor $(7,9 \%)$, mencionou que recebe apoio, quando afirma sua escolha: "Na maioria das vezes não tenho retorno negativo, outras pessoas comentam que têm o mesmo plano e muitos até falam que no mundo atual está muito difícil a criação de um filho. Observo que esta opção da não maternidade está cada vez mais ampla”. Uma das participantes relatou apoio quando afirmou sua decisão para uma profissional da área da saúde, área em que geralmente se direciona o cuidado a partir da expectativa pela maternidade:

Recentemente uma enfermeira questionou quando da colocação do DIU Mirena se eu já tinha filhos e quando falei que não pretendia ouvi dela: "que legal!! você sabe realmente o que quer e principalmente o porquê desta escolha; e não se submete ao que a sociedade vem impondo há anos a todas nós mulheres interessante seu posicionamento isso me abre outra perspectiva sobre o assunto, obrigada acabou me ajudando.

Apenas 2\% das mulheres afirmaram não compartilhar suas decisões e, nesses depoimentos, apareceram conteúdos relacionados à aceitação por parte das pessoas, contudo geralmente associados à questão da idade da mulher: "Hoje com 38 anos já não ouço mais tantas críticas”. 


\section{Maternidade é benção}

Por fim, na última categoria, agrupamos elementos que se relacionam aos efeitos da verbalização da escolha, que se materializam por meio de assertivas que, alinhadas a afirmações de que a maternidade é sagrada, é sinônimo de felicidade e, portanto, deve ser vivida por todas as mulheres, procuram argumentar no sentido do convencimento.

Algumas afirmações passam por uma indiferença inicial: "escolha é sua”, contudo, segundo as participantes, o "julgamento fica implícito”, somando-se quase sempre a um "ar de pena”. Mas a maioria das respostas trazem explicitamente a obrigatoriedade de ter filhos, baseando-se em justificativa de caráter biológico: "Ao menos um tem que ter"; "mulher foi feita para ter filho"; "isso não é natural”; "Eu acho que você ainda vai querer ter, toda mulher tem esse instinto". Falase também em manutenção da família, no sentido de perpetuação da espécie: "você precisa dar continuidade a sua família”.

Outros depoimentos vão no sentido de avaliação do caráter da mulher que opta por não ter filhos: "Que é egoísta, não gosta de crianças”; “já fui chamada de árvore seca por isso.”. "Louca” "árvore seca” e "egoísta” parecem ser palavras comuns, o que coloca as mulheres não mães em um lugar de estigmatização social. Seguindo-se a isso, são apresentados questionamentos acerca dos motivos, julgamentos e enumeradas possíveis "consequências" dessa escolha: "escuto muito que eu posso mudar de ideia... e que eu vou me arrepender de não ter filhos.... que não terei ninguém pra cuidar de mim na velhice...e coisas do gênero"; "Ah, você vai se arrepender. Ah, toda mulher tem que ser mãe...".

$\mathrm{O}$ arrependimento vem alicerçado no argumento de que a maternidade está relacionada à feminilidade, é "plenitude", "amor puro", "bênção"; “que é a melhor coisa do mundo, que não tem como nao gostar de crianças”. Destaca-se nesse último comentário a afirmação, baseada no senso comum de que mulheres que não querem ter filhos não gostam de crianças. Uma das participantes mencionou ainda que recebeu como resposta que “deveria adotar um bebê”. Essa resposta nega completamente a possibilidade de uma mulher ter escolhido não ser mãe, pressupondo que: ou a mulher não pode ter filhos pela via biológica; ou não quer passar pela experiência da gestação e/ou parto. Destaca-se nessa resposta ainda o fato de que parece que não foi possível ouvir que uma mulher pode não querer ser mãe, tanto que a opção que se dá é a adoção, ou seja, de todo modo passar pela experiência da maternidade parece ser realmente um imperativo.

Uma participante relata a possibilidade de compreensão acerca da escolha pela não maternidade, contudo não sem esforço:

Em uma direção, comentários que de algum modo parecem recriminar nossa decisão ou que funcionam como uma espécie de aconselhamento grátis: meu casamento irá 
melhorar, ainda vou mudar de ideia sobre a maternidade, que ter filhos é bom. Mas, à medida que argumento com calma, as pessoas mudam seu posicionamento e admitem que dá muito trabalho e é extremamente cansativo, que muda a vida (e percebo que na maioria das vezes não é algo tão positivo), além de exigir da família outro tipo de planejamento financeiro.

O depoimento acima coloca a possibilidade de diálogo acerca dos prós e contras da experiência da maternidade, contudo, parece mais comum quando uma mulher que é mãe conversa com outra que demonstra não ter o mesmo desejo, a argumentação ir na direção do convencimento, como mencionamos acima. A esse respeito, destaca-se a justificativa, sempre necessária, no caso da escolha pela não maternidade, enquanto a opção pela maternidade nunca é questionada e, portanto, não carece de justificativas, como já discutiu Donath (2017).

Por fim, precisamos mencionar que, embora tenhamos desenvolvido uma investigação destinada a mulheres que haviam decidido pela não maternidade, o que estava explícito no convite para participar da pesquisa, algumas participantes parecem não ter propriamente optado pela não maternidade, mas foram levadas a isso por vários motivos: não ter um companheiro, fatores de saúde/idade, trabalho, etc. Entretanto, há que se ponderar que, mesmo nessas circunstâncias, houve uma escolha pela não maternidade, uma vez que tais fatores não são propriamente impeditivos para ser mãe, embora possam pesar na decisão. Ainda, não foram elencados nas respostas em quantidade significativa motivos tais como o mundo de hoje não ser um bom lugar para crianças, gasto despendido; questões estéticas, sexuais ou de relacionamento.

Nessa discussão acerca da não maternidade, algo é certo: trata-se de uma escolha extremamente difícil de bancar, sobretudo pelo peso social que possui na vida de uma mulher. O depoimento com o qual finalizamos este texto, e que fala da resposta obtida quando se verbaliza a opção pela não maternidade, resume os vários elementos que perpassam essa decisão, bem como as dúvidas e inseguranças que são geradas nesse processo:

Que eu sou casada e, portanto, devo ser mãe; que vou me sentir solitária quando ficar mais velha; que não vai ter ninguém (filho) pra cuidar de mim na velhice, ou quando ficar doente; que meu casamento vai entrar em crise/vai ficar morno e chato e um filho me 'livraria' (entreteria?) disso - parece que um casal sem filhos não pode pertencer à sociedade (porque é errado). É tanta pressão com relação a isso que às vezes digo que vou sim pensar em ser mãe depois que terminar o doutorado (já está terminando) e acho que sei que não quero mesmo ser mãe - apesar de minha ginecologista ter me dito estes dias que eu não posso descartar a possibilidade até dizer que 'tenho CERTEZA' desta decisão. Às vezes até eu fico 
incerta porque a 'certeza da maternidade' - essa força exterior - é tão forte que a gente chega a achar que quem sabe/talvez a ideia mude. Mas acho - quase absolutamente - que não.

\section{Considerações finais}

Tendo em vista as mudanças nas estruturas familiares (ALVES et al., 2017), o crescente número de mulheres que vêm sendo mães tardiamente ou optando por não ter filhos (DONATH, 2016), o presente trabalho teve por objetivo colocar em pauta a questão da não maternidade como opção, por meio de relatos de mulheres que optaram por não ter filhos. Os dados foram coletados por meio de questionário online com perguntas abertas e fechadas que versavam acerca da decisão por não ter filhos, ou seja, poderiam participar mulheres que não fossem e não desejassem ser mães por decisão própria, e não por outros motivos ou fatores. Destaca-se o fato de que responderam ao instrumento 310 mulheres, no espaço de tempo de 15 dias de divulgação por meio das redes sociais das pesquisadoras, o que indicia a necessidade de se falar sobre o tema. As participantes eram, em sua maioria, heterossexuais, estando em algum tipo de relacionamento, financeiramente estáveis, com idades entre 26 a 33 anos. Outro fator relevante é que grande parte possuía formação de ensino superior.

As respostas permitiram uma discussão em torno do fato de que permanecem produzindo efeitos discursos que enfatizam o papel da mulher como mãe, compreendendo essa função como natural, enquanto a paternidade é vista como função social, conforme afirmou Scott (1998). Nota-se também que a cobrança social é contínua, principalmente quando se trata de uma mulher em um relacionamento estável e com boas condições financeiras, visto que, na ótica social, a junção desses elementos é o passo inicial para constituir família.

Os relatos trazidos pelas participantes apresentam justificativas que não possuem, necessariamente, relação com a criança, mas, sim, com os efeitos que a maternidade produz. Ou seja, a decisão em não ser mãe tem mais a ver com o fato de que os cuidados com a criança ainda são função predominante da mulher, do que propriamente com o processo de gravidez, parto ou características inerentes à criança. Desse modo, não é nem o processo, nem o produto o problema, mas a forma como a maternidade é exercida enquanto prática social.

Tendo em vista esse conteúdo geral, dividimos as falas apresentadas pelas mulheres em três categorias: "maternidade compulsória", "arrependimento" e "maternidade é bênção". Essas categorias dizem de um processo de compreensão da escolha pela não maternidade que passa por uma estrutura social que coloca a maternidade como experiência absolutamente ligada ao feminino, de modo que a segunda categoria fala dos efeitos quando uma mulher opta por não passar 
por essa experiência. Por sua vez, a última categoria aborda os sentidos em torno da maternidade, que ainda a colocam como lugar de felicidade, amor único e incondicional, a despeito de diferentes falas em torno das dificuldades inerentes a essa experiência. Percebemos que há mais possibilidade de afirmar o não desejo pela maternidade, o que se registra pela quantidade de participantes e pelos relatos de manifestações de apoio, compreensão ou, minimamente, aceite por parte das outras pessoas. Obviamente, ainda aparecem as tentativas de convencimento e os motivos relacionados ao amor materno, à experiência não ser comparável a outras, à possibilidade do arrependimento. A religião também aparece como fonte expressiva, mas parece ter diminuído seu potencial de afetar ou mudar a opinião das mulheres, o que pode ser explicado pelas características da amostra (embora não tenhamos coletado dados acerca de religião).

O trabalho sinalizou para algo que vem se colocando nos últimos anos, que é a possibilidade de dizer sobre o desejo de não ser mãe. Contudo, isso não é possível sem justificativas, dada a pressão social em torno das mulheres, relatada nas pesquisas sobre o tema. Inclusive, cabe aqui uma autocrítica: a própria proposição do instrumento que utilizamos nesta pesquisa reproduz a necessidade de se justificar essa escolha. Nesse sentido, é preciso considerar que a escolha pela maternidade não carece de justificativa: a mulher grávida não precisa justificar por que vai ser mãe, afinal "é natural"; em contrapartida, a mulher que decide não ter filhos, precisa justificar o tempo todo, e somente muito recentemente tem sido possível justificar pelo próprio desejo e não por outros motivos inerentes à sua história de vida.

Por fim, faz-se necessário mencionar que o instrumento possibilitou receber muitos dados, contudo não foi possível acessar um nível maior de detalhamento no conteúdo dessas respostas, como nas outras pesquisas que mencionamos na revisão bibliográfica que entrevistaram as participantes (PATIAS \& BUAES, 2009; 2012; RIOS E GOMES, 2009; FIDELIS \& MOSMANN, 2013; DONATH, 2016). Por exemplo, em uma das perguntas acerca do motivo pelo qual a participante havia optado por não ser mãe, uma delas respondeu apenas: "assistente social” e não pudemos obter outros dados importantes para compreender tal conteúdo.

Outro ponto importante a ser destacado é que, em pesquisa anterior, realizada pelas mesmas autoras, que se propôs a coletar depoimentos sobre não maternidade por opção em blogs e ambientes online (2013), as falas das mulheres apresentavam um posicionamento defensivo, com críticas voltadas à existência de crianças no mundo, argumentos em relação ao mundo não ser bom para receber crianças, mencionando também custo para se ter e manter uma criança, argumentos que não foram mencionados ou apareceram em pequeno número na pesquisa atual. Acreditamos que isso sinaliza para um deslizamento das falas das mulheres em torno da maternidade, sendo possível expressar o não desejo por essa experiência. 


\section{Referências}

ALVES, José Eustáquio Diniz; CAVENAGUI, Suzana Marta; CARVALHO, Angelita Alves de; SOARES, Maira Covre Sussai. Meio século de feminismo e o empoderamento das mulheres no contexto das transformações sociodemográficas do Brasil. In: BLAY, Eva Alterman; AVELAR, Lucia (Orgs). 50 anos de feminismo: Argentina, Brasil e Chile. 1a ed. São Paulo: Editora da Universidade de São Paulo (Fapesp), 2017, p. 15-54.

BADINTER, Elisabeth. Um amor conquistado: o Mito do Amor Materno. 1a ed. Rio de Janeiro: Nova Fronteira, 1985.

BARDIN, Lawrence. Análise de Conteúdo. São Paulo: Edições 70, 2011.

BEAUVOIR, Simone. O segundo sexo: a experiência vívida - vol. 2. za ed. Rio de Janeiro: Nova Fronteira, 1980.

BRASIL, IBGE. Pesquisa Nacional de Saúde. Idade média que tinham as mulheres de 18 a 49 anos de idade quando tiveram a primeira gravidez, 2013.

DONATH, Orna. Mães Arrependidas: uma outra visão da maternidade. 1 ed. Rio de Janeiro: Civilização Brasileira, 2017.

FIDELIS, Daiana Quadros; MOSMANN, Clarisse Pereira. A não maternidade na contemporaneidade: um estudo com mulheres sem filhos acima dos 45 anos. Aletheia. n. 42, dez, 2013, p. 122-135.

GIL, Antônio Carlos. Como elaborar projetos de pesquisa. 4 ed. São Paulo: Atlas, 2010.

MANSUR, Luci Helena Baraldo. Experiências de mulheres sem filhos: a mulher singular no plural. Revista Psicologia, Saúde e Profissão. São Paulo: Casa do Psicólogo, 2003, p. 2-11.

PATIAS, Naiana Dapieve, BUAES, Caroline Stumpf. Não tem filhos? Por quê? Disc. Scientia. Ciências Humanas. vol. 10, n. 1, 2009, p. 121-133.

PATIAS, Naiana Dapieve, BUAES, Caroline Stumpf. “Tem que ser uma escolha da mulher"! Representações de maternidade em mulheres não-mães por opção: Psicologia E Sociedade, vol. 24, núm. 2, maio-agosto/2012, p. 300-306.

RIOS, Maria Galrão; GOMES, Isabel Cristina. Casamento contemporâneo: revisão de literatura acerca da opção por não ter filhos. Estudos de Psicologia. vol. 26, n. 2, abriljunho, 2009a, p. 215-225. 
RIOS, Maria Galrão; GOMES, Isabel Cristina. Estigmatização e conjugalidade em casais sem filhos por opção. Psicologia em Estudo, vol 14, n. 2, abril-junho, 20ogb, p. 311-319.

SCOTT, Joan Wallach. A Cidadã Paradoxal: as feministas francesas e os direitos do homem. 1a ed. Florianópolis, Santa Catarina: Mulheres, 2002.

SANTOS, Kátia Alexsandra dos. As vicissitudes da mulher contemporânea: ser mãe ou não ser?. Letra Magna, v. 9, 2013, p. 1-16.

SCAVONE, Lucila. A maternidade e o feminismo: diálogo com as ciências sociais. Cad. Pagu, n. 16, 2001, p. 137-150.

SOARES, Izabel Cristina; SANTOS, Kátia Alexsandra dos. "Eu não quero ter filhos: o discurso feminino sobre a não maternidade por opção. Relatório final de Iniciação Científica. Pró-Reitoria de Pesquisa, Universidade Estadual do Centro-OesteUNICENTRO, 2013.

VENÂNCIO, Renato Pinto. Maternidade Negada. In: DEL PRIORE, Mary. História das Mulheres no Brasil. 10a ed. São Paulo: Contexto, 2012, p. 189-222.

400 Recebido em 20/03/2020.

Aceito em 30/10/2020. 